\title{
The Ontogeny of Human Stupidity
}

\section{James F Welles*}

Free Lance Writer, USA

Received: May 11, 2018; Published: May 16, 2018

*Corresponding author: James F Welles, Free Lance Writer, USA

\section{Opinion}

The wonder of human culture is that anyone manages to grow up with anything like sense and sanity. Consider the fact that most people start life with the handicap of parental love. Of all forms of emotionally induced blindness, this is the blindest, and most of us are lucky enough to get a double dose. As with others who love [1], parents are blind because they want to be, and for nearly two decades, the child is helpless to escape the best efforts of his parents to distort his selfimage and sense of importance [2]. Whatever limitations culture may have, it certainly is efficient at transmitting stupidity from one generation to the next (as well as developing it anew). Children receive a basic lesson from their parents and other adults who gain some peculiar pleasure in denying reality to them. It is quite common to say to a small child, "What a big boy you are" [3]. Statements contrary to the obvious may be more comforting than the truth-"My, what a scrawny little runt you are!"- and have the added advantage of preparing the child for the adult world in which accuracy is too commonly sacrificed to diplomacy.

A In the first year, the child passes through a phase of cerebella, motor control [4] and forms a basic information processing schema. This is the first step in the construction of a general religious belief system which will guide and limit future behavior. At this time, the child develops a fundamental sense of trust or mistrust [5], which is another source of future stupidity: later on, the individual will find himself mistakenly trusting the untrustworthy or suspiciously dismissing honest people with sincere intentions. A cognitive correlate of trust is the concept of object permanence, which is formed by the age of 18 months. By this age, the child can represent by mental image objects no longer in sight. The underlying assumption is that objects are consistent — that they remain the same not only when viewed from different angles or distances but even when they cannot be viewed at all. Thus, different perceptions can be associated with a constant object [6]. This has great potential for stupidity, in that an object may change and yet people will cling to their original image rather than adjust to the time altered reality.

The age of two years is the age of language, with actions and objects being represented by verbal as well as visual symbols [7].
Classifying and grouping the symbols is accomplished according to the specific language of the social group. This is the process by which information is sorted and organized into categories which may or may not reflect relevant relationships in the environment. Along with the development of a child's cognitive world of ideas, a sense of rules and order also develops and undergoes transformation with maturation. For a young child, a rule is reality and is sacred because it is traditional. Even some adults never get beyond this stage, and, indeed, the basic rules of life, whatever they are, do not change. The older child comes to realize that stated rules are expressions of mutual agreement which function by promoting social cooperation through individual constraint [8].

Although the idea of rules may change, the system of assumed world order the young child inherits from his parents is a moral necessity to him. As he matures, he will be forced to resort to reason when his rules are challenged by people with other rules or by an amoral environment. He then may be pulled in a number of directions while trying to impose unity on the chaos of this experience [9]. For all their inventive play, young children are basically conservative. They hate change, as anyone who has dared alter a word in a bedtime story well knows. Their cognitive expectations are very precise with daily routine providing stability [10] and a sense of safety in a strange, often unpredictable world [11]. Oddly enough, the extreme trauma of losing a parent in early childhood can induce a schema busting persona. The survivor of such an experience is likely to break the frame of the known worldof what is known and assumed [12]. Generally, however, the more uncertain the external world appears, the more tenaciously the schema is held and although it may occasionally if not chronically induce stupidity, its common presence indicates that, over all, it must be truly adaptive.

\section{Reference}

1. Plato Ca, 370 B.C. Phaedrus. Love is listed as a fourth type of mania afterpoetry, prophesy and religious ecstacy.

2. Pitkin W (1932) A Short Introduction to the History of Human Stupidity. Simon and Schuster; New York. 438. 
3. Freud A(1966)The Ego and the Mechanisms of Defense. InternationalUniversities Press; New York. 84.

4. Bronowski JThe Ascent of Man. Little, Brown \& Co.; Boston, MA. 51.

5. Erikson E (1974) Dimensions of a New Identity: The 1973 Jefferson Lectures in the Humanities. Norton; NY.

6. Piaget J(1932)The Moral Judgment of the Child. Macmillan; New York. Btw,Piaget was very much a Lockian "Nurturist".

8. Ibid.

9. Ibid.

10. Clinton H(1993) Liz Carpenter Lecture at the University of Texas.

11. Smith R, Sarason I,Sarason B(1982) Psychology: The Frontiersof Behavior. Harper \& Row; New York 366.

12. Mezan P, Dr. Quoted in Gladwell (2013) 153f.

7. Ibid.

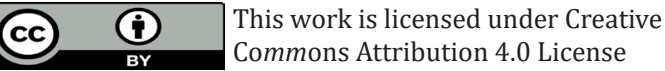

Submission Link: https://biomedres.us/submit-manuscript.php

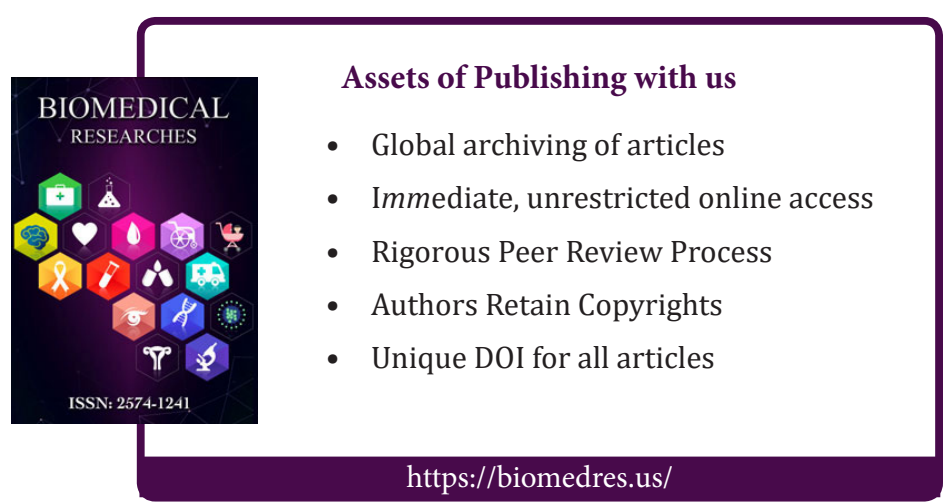

